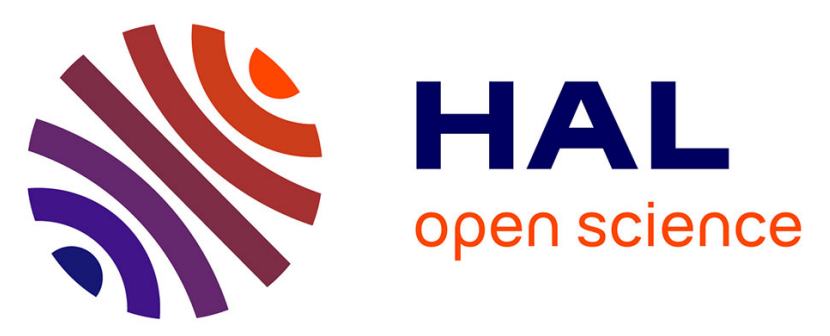

\title{
Transfer hydrogenation of N-benzylideneaniline catalyzed by ruthenium complexes with pincer-type phosphorus nitrogen ligands using propan-2-ol as the hydrogen source
}

S. A. Moya, C. Negrete-Vergara, K. Brown, V. Artigas, M. Fuentealba, V. Guerchais, P. Aguirre

\section{To cite this version:}

S. A. Moya, C. Negrete-Vergara, K. Brown, V. Artigas, M. Fuentealba, et al.. Transfer hydrogenation of N-benzylideneaniline catalyzed by ruthenium complexes with pincer-type phosphorus nitrogen ligands using propan-2-ol as the hydrogen source. Catalysis Communications, 2017, 99, pp.150-153. 10.1016/j.catcom.2017.04.026 . hal-01578552

HAL Id: hal-01578552

https://hal-univ-rennes1.archives-ouvertes.fr/hal-01578552

Submitted on 16 May 2018

HAL is a multi-disciplinary open access archive for the deposit and dissemination of scientific research documents, whether they are published or not. The documents may come from teaching and research institutions in France or abroad, or from public or private research centers.
L'archive ouverte pluridisciplinaire HAL, est destinée au dépôt et à la diffusion de documents scientifiques de niveau recherche, publiés ou non, émanant des établissements d'enseignement et de recherche français ou étrangers, des laboratoires publics ou privés. 
Transfer hydrogenation of $\mathrm{N}$-benzylideneaniline catalyzed by ruthenium complexes with pincer-type phosphorus nitrogen ligands using propan-2-ol as the hydrogen source.

S. A. Moya ${ }^{2}$, C. Negrete-Vergara ${ }^{1}$, K. Brown ${ }^{2}$, V. Artigas ${ }^{3}$, M. Fuentealba ${ }^{3}$, V. Guerchais ${ }^{4}$, P.Aguirre ${ }^{1 *}$

${ }^{1}$ Universidad de Chile, Facultad de Ciencias Químicas y Farmacéuticas, Casilla 233, Santiago 1, Chile. paguirre@ciq.uchile.cl. Fax 56-2-7370567.

${ }^{2}$ Universidad de Santiago de Chile, Facultad de Química y Biología, Av. Libertador Bernardo O'Higgins 3363, Casilla 40, Correo 33, Santiago, Chile. sergio.moya@usach.cl

${ }^{3}$ Pontificia Universidad Católica de Valparaíso, Facultad de Ciencias, Avenida Universidad 330, Valparaíso, Chile.

${ }^{4}$ UMR 6226 CNRS-Université de Rennes 1, Sciences Chimiques de Rennes, Campus de Beaulieu, 35042 Rennes, France. 


\section{Abstract}

Ruthenium complexes containing phosphorus-nitrogen, pincer-type (NPN) ligands show high activities and selectivities in the transfer hydrogenation of $\mathrm{N}$ benzylideneaniline using propan-2-ol as the hydrogen source. Such is the case of complexes $\mathrm{RuCl}_{2} \mathrm{PPh}_{3}\left(\mathrm{PPh}(\mathrm{NHPy})_{2}\right)$ (1) and $\mathrm{RuCl}_{2} \mathrm{PPh}_{3}\left(\mathrm{PPh}(\mathrm{NHPyMe})_{2}\right)$ (2) which also show TOFs $5989 \mathrm{~h}^{-1}$ and $5928 \mathrm{~h}^{-1}$, respectively. These remarkable results were obtained after only 10 minutes of reaction using a 1000/1 substrate/catalyst ratio. 


\section{Introduction}

Transfer hydrogenation of ketones has several advantages over using molecular hydrogen in homogeneous catalysis. The former makes use of simple equipment, low catalyst loading, safe manipulation, and easy removal of volatile by-products. The good performance of $\left[\mathrm{RuCl}_{2}\right.$ (diphosphane)(diamine)] complexes in the asymmetric hydrogenation of ketones [1] has increased the great interest to study the reaction looking at the reactivity of $\mathrm{Ru}$ (II) complexes based on phosphorus and amino ligands $[2,3]$.

Indeed, the transfer hydrogenation of ketones has been widely and successfully studied using ruthenium complexes [4]. In many cases, propan-2-ol is the preferred hydrogen donor/solvent of choice since it is stable, non-toxic, readily available and inexpensive [4,5]. In the hydrogenation using homogeneous catalysis, the ligands play an important role in the improved performance of organometallic catalysts with properties such as chelating effect, hemilability, and stability. Often times, additional functional groups are required in the ligands in order to improve the catalytic behavior. For example, the $\mathrm{NH}$ moieties in organometallic catalysts can serve as coordination groups, hydrogen bonding donors, hydrogen bonding acceptors, and/or proton sources [6]. Although the hydrogenation of imines using transition metals as catalysts is usually conducted using molecular hydrogen, some authors prefer propan-2-ol acting as the hydrogen source [7-10]. In this regard, PNchelate ligands or NPN ligands have attracted considerable attention in both coordination chemistry and catalysis due to the unusual electronic properties and the pronounced hemilabile character that arises when two very different binding sites are present $[11,12,13]$. Such is the case of a $R u$ catalyst containing $P-N$ ligands giving rise to high activities in the transfer hydrogenation of ketones [14]. In the same vein, Kirchner and co-workers [15] have described the synthesis and catalytic activities of $\mathrm{Mn}(\mathrm{I})$ and $\mathrm{Fe}(\mathrm{II})$ complexes containing PNP ligands in the coupling reaction of alcohols and imines. Here an interesting mechanism takes place whereby the $\mathrm{NH}$ group of the PNP ligands is deprotonated, yielding molecular hydrogen.

Besides using ruthenium catalysts, the transfer hydrogenation of unsaturated compounds such as ketones or imines has been studied with other metals in the catalyst. For instance, rhodium, iron, and iridium catalysts display a very effective behavior in this reaction $[16,17]$. However, the ruthenium catalysts are very versatile since they have a larger number of applications in homogenous hydrogenations.

Our group has studied the hydrogenation of imines using ruthenium complexes with polypyridine ligands [18-20] which lead to high conversions and selectivity. We found that an important problem in this reaction is the instability of the substrate under basic conditions. Transfer hydrogenation of polar functional groups has 
significantly contributed to the recent growth in organic synthesis methodologies. When propan-2-ol is used as the hydrogen donor, the only by-product formed is acetone, which can be easily removed by distillation during workup. We report here the synthesis and characterization of ruthenium complexes containing phosphorusnitrogen, pincer-type ligands, and their catalytic activities in the transfer hydrogenation of $\mathrm{N}$-benzylideneaniline (scheme 1). The synthesized complexes show $100 \%$ conversion in the hydrogenation of the said substrate under the conditions described below.

\section{Results and discussion}

The complexes were synthesized using two different precursors: $\mathrm{RuCl}_{2}\left(\mathrm{PPh}_{3}\right)_{3}$ and $\mathrm{Ru}(\mathrm{Cl})(\mathrm{CO})(\mathrm{H})\left(\mathrm{PPh}_{3}\right)$. This synthesis strategy yielded two sets of metal complexes whose structures include the pincer ligand and the ligands chloride or carbonyl (see scheme 1), (see the experimental section, Supplementary Material).

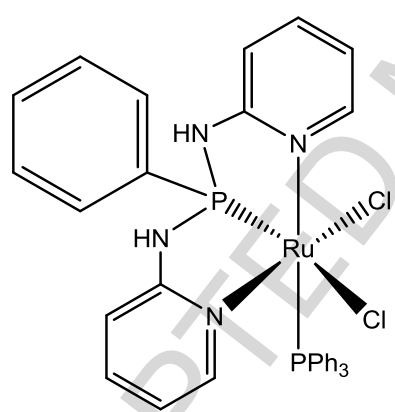

Complex 1

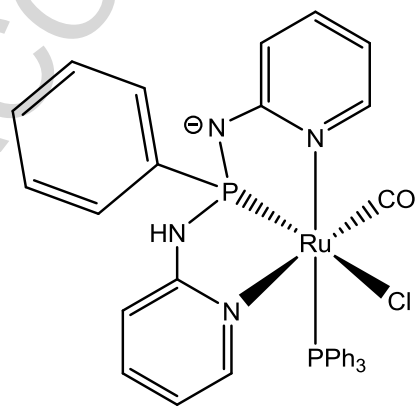

Complex 3

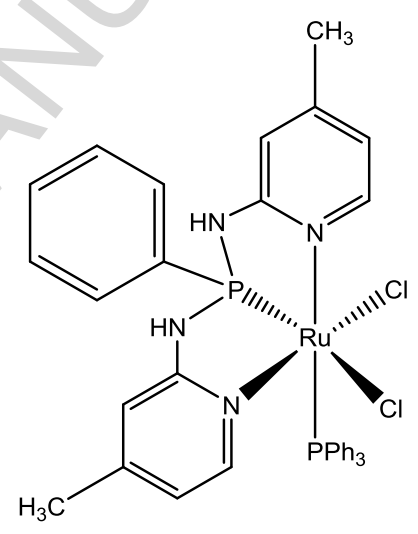

Complex 2

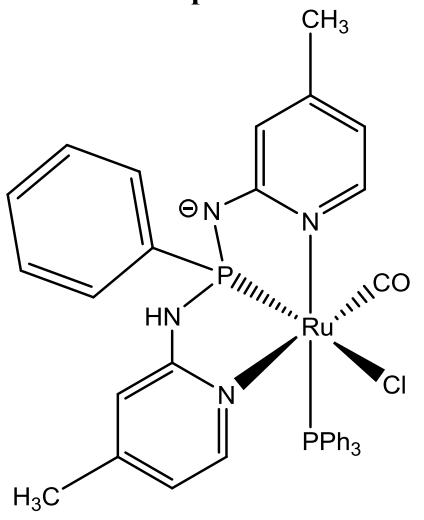

Complex 4

Scheme 1. Ruthenium complexes containing pincer-type phosphorus-nitrogen ligands(NPN) used as catalysts in the hydrogenation of N-benzylideneaniline. 
The complexes were characterized by nuclear magnetic resonance, elemental analysis, and X-ray diffraction. The ${ }^{1} \mathrm{H}-\mathrm{NMR}$ spectra are in agreement with the proposed structures for the prepared compounds, with a shift of the signals relative to the free ligand. On the other hand, the ${ }^{31} \mathrm{P}\{\mathrm{H}\} N \mathrm{~N}$ R spectrum indicates that the signal of the free ligand NPN moves from $44.3 \mathrm{ppm}$ to $132.7 \mathrm{ppm}$ for the complex 1. The ${ }^{31} \mathrm{P}\{\mathrm{H}\} \mathrm{NMR}$ spectrum for complex 1 shows two signals at $132.7 \mathrm{ppm}(\mathrm{d}, 1 \mathrm{P}$, $\left.{ }^{2} \mathrm{JP}_{\mathrm{P} P}=37 \mathrm{~Hz}, \mathrm{NPN}\right)$ and $42.7 \mathrm{ppm}\left(\mathrm{d}, 1 \mathrm{P},{ }^{2} \mathrm{JP}_{\mathrm{P} P}=37 \mathrm{~Hz}, \mathrm{PPh}_{3}\right)$ and complex 2 shows signals at $133.5 \mathrm{ppm}\left(\mathrm{d}, 1 \mathrm{P},{ }^{2} \mathrm{JP}_{\mathrm{P}-\mathrm{P}}=37 \mathrm{~Hz}, \mathrm{NPN}\right)$ and $42.6 \mathrm{ppm}\left(\mathrm{d}, 1 \mathrm{P},{ }^{2} \mathrm{~J}_{\mathrm{P}-\mathrm{P}}\right.$ $=37 \mathrm{~Hz}, \mathrm{PPh}_{3}$ ). The assignments are in agreement with the proposed structures; the phosphorous atoms are in the cis-configuration (see Supplementary Material). The complexes 3 and $\mathbf{4}$ show similar ${ }^{31} \mathrm{P}\{\mathrm{H}\} \mathrm{NMR}$ spectra. The two signals of complex 3 appear at $125.3 \mathrm{ppm}\left(\mathrm{d}, 1 \mathrm{P},{ }^{2} \mathrm{JP}_{\mathrm{P}}=25 \mathrm{~Hz}, \mathrm{NPN}\right)$ and $48.8 \mathrm{ppm}(\mathrm{d}, 1 \mathrm{P}$, ${ }^{2} \mathrm{JP}_{\mathrm{P}-\mathrm{P}}=26 \mathrm{~Hz}, \mathrm{PPh}_{3}$ ), and for the complex 4 the equivalent signals appear at 124.8 $\mathrm{ppm}\left(\mathrm{d}, 1 \mathrm{P},{ }^{2} \mathrm{JP}_{\mathrm{P}-\mathrm{P}}=26 \mathrm{~Hz}, \mathrm{NPN}\right)$ and $48.3 \mathrm{ppm}\left(\mathrm{d}, 1 \mathrm{P},{ }^{2} \mathrm{~J}_{\mathrm{P}-\mathrm{P}}=26 \mathrm{~Hz}, \mathrm{PPh}_{3}\right)$. Regarding elemental analysis, we believe that it confirms the proposed formula and that relatively small variations that were detected may be due to the presence of a tiny amount of residual solvent in the complexes. For each series of compounds, it was possible to obtain the respective crystal structures, which confirm the proposed structures.

The crystal structure of complex 1 indicates a distorted octahedral geometry with the phosphorus in a cis configuration (see figure 1). The crystallographic properties are summarized in tables 1SM, 2SM, 3SM (Supplementary Material) and the distances and angles show little distortion for the octahedral configuration.[21,22]. 


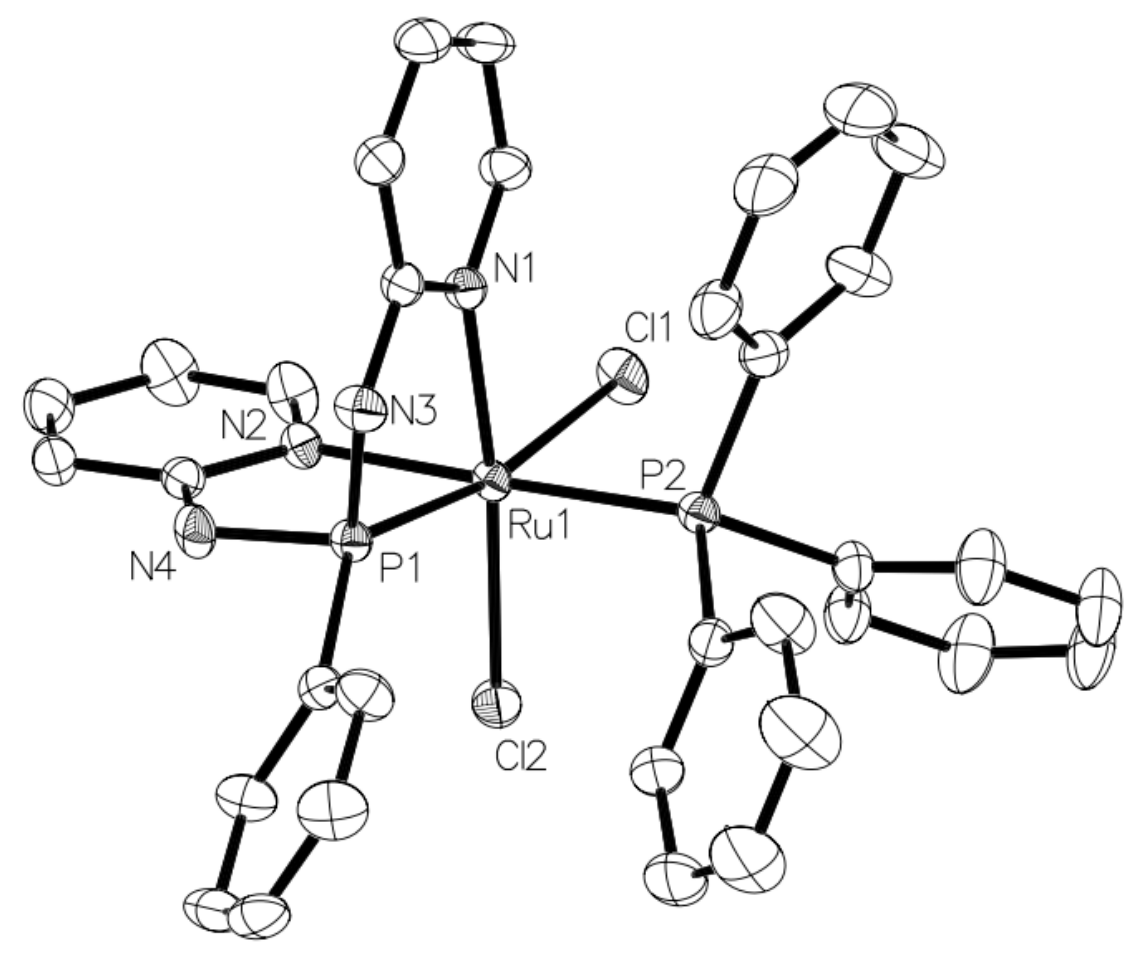

Figure 1 Crystal structure for complex 1

The crystallographic properties of complex 4 are summarized in table $4 S M$ and the distances and angles are shown in tables 5SM and 6SM (Supplementary Material). Complex 4 crystallizes in a distorted octahedral geometry with the phosphorus having a cis configuration (see Supplementary Material).

Since we expected to obtain a ruthenium complex with a hydride species (complexes $\mathbf{3}$ and $\mathbf{4}$, we decided to observe the follow-up of the formation of these complexes in the early steps of the reaction. To carry out this experiment we mixed one equivalent of the ligand and one equivalent of the ruthenium precursor in a Schlenk tube, then deuterated benzene was added and the mixture was stirred and heated at $80^{\circ} \mathrm{C}$ for 30 minutes ( see Supplementary Material). Once the mixture cooled down to room temperature, a ${ }^{1} \mathrm{H}-\mathrm{NMR}$ and ${ }^{31} \mathrm{P}\{\mathrm{H}\} N \mathrm{NR}$ spectra were performed. A likely mechanism for this synthesis is shown in scheme 2.

The ${ }^{31} \mathrm{P}\{1 \mathrm{H}\}-N M R$ spectrum of compound $(\mathrm{A})$, which is the actual intermediate, shows three distinct phosphorus signals. The one shifted at high field $(-4.1 \mathrm{ppm})$ corresponds to a molecule of triphenylphosphine that has been uncoordinated to give the coordination of phosphorus of the NPN ligand at $64.5 \mathrm{ppm}$ (t, $1 \mathrm{P},{ }^{2} \mathrm{JP}-\mathrm{P}=$ $18.1 \mathrm{~Hz}$ ) which is found in a trans configuration with respect to the hydride species $(\mathrm{JH}-\mathrm{P}=120 \mathrm{~Hz})$. The signal at $39.3 \mathrm{ppm}(\mathrm{d}, 2 \mathrm{P}, \mathrm{JP}-\mathrm{P}=18.3 \mathrm{~Hz})$ corresponds to 
the triphenylphosphines coordinated axially to each other, which are in the cis configuration with respect to both the hydride and the phosphorus of the NPN ligand. Note that there is a plane of symmetry involving the following: chloro, carbonyl, hydride and the phosphorus atom of the NPN ligand. This experimental evidence shows that phosphorus is the element that is coordinated preferentially to the ruthenium.

In a second step, a triphenylphosphine molecule $\left(\mathrm{PPh}_{3}\right)$ is uncoordinated, which leads to intermediate $(\mathbf{B})$ where the phosphorus-nitrogen ligand coordinates to the metal in a bidentate (PN) form. Finally, the pincer ligand changes its coordination to tri-coordinated to fill the coordinative vacant generated by the outgoing hydride, after which compound (C) appears. The hydride ligand of the precursor reacts with the hydrogen of the $\mathrm{N}-\mathrm{H}$ fragment to generate molecular hydrogen. The deprotonation process for pincer ligands has been described by Kirchner et al. [13].

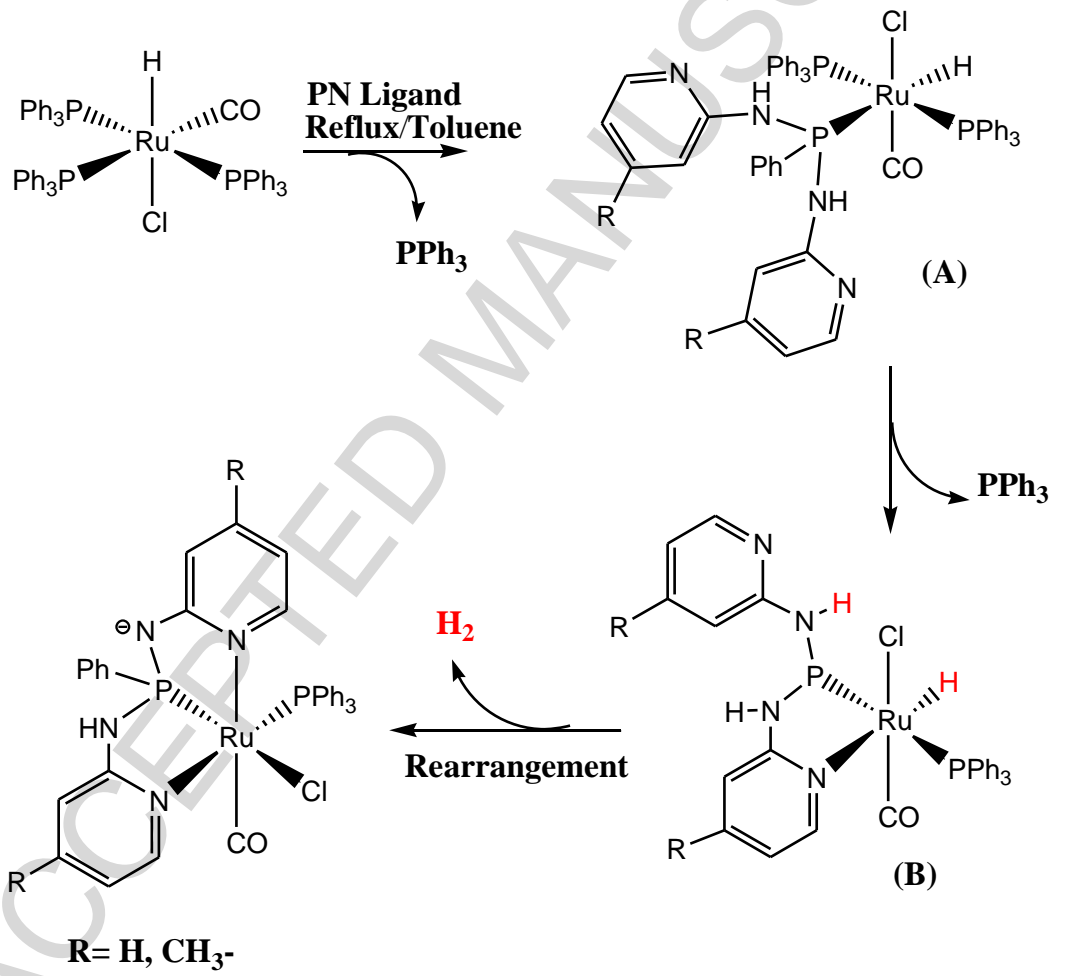

(C)

Scheme 2. Likely mechanism for the dehydrogenation of $\mathrm{Ru}(\mathrm{Cl})(\mathrm{CO})(\mathrm{H})\left(\mathrm{PPh}_{3}\right)_{3}$ complex containing pincer-type ligands

The hydrogen was detected by GC using a thermal conductivity detector. The crystal structure of complex $\mathbf{4}$ is consistent with a distorted octahedral geometry whereby the two phosphorus atoms are in a cis configuration and one $\mathrm{NH}$ group appears deprotonated.

\section{Catalytic results}


Table 1. Catalytic activities for the hydrogenation of $\mathrm{N}$-benzylideneaniline catalyzed by ruthenium complexes containing pincer-type phosphorus-nitrogen ligands.

\begin{tabular}{|c|c|c|c|}
\hline Catalyst & $\begin{array}{c}\text { Reaction } \\
\text { time (min) }\end{array}$ & Conversion & $\begin{array}{c}\text { TOF } \\
\mathrm{h}^{-1}\end{array}$ \\
\hline 1 & 10 & 98 & 5868 \\
\hline 2 & 10 & 99 & 5928 \\
\hline 3 & 180 & 10 & 3.3 \\
\hline 4 & 180 & 5 & 1.3 \\
\hline
\end{tabular}

Substrate/catalyst ratio: 1000/1 for complexes 1 and 2 and 100/1 for complexes 3 and 4 ; catalyst $/ \mathrm{NaOH}$ ratio $=40$; solvent propan-2-ol; temperature $=$ reflux.

The catalysts were studied in the transfer hydrogenation of $\mathrm{N}$-benzylideneaniline using propan-2-ol as the source of hydrogen. Catalysts 1 and 2 showed high activities and selectivity in the reaction. On the other hand, catalysts 3 and $\mathbf{4}$ were not active in the reaction (table 1). The turnover frequencies (TOF) for the complexes 1 and 2 were $5868 \mathrm{~h}^{-1}$ and $5928 \mathrm{~h}^{-1}$, respectively. The catalytic systems remained stable and the catalytic activity was maintained after four recharges made in the reactor. The TOF values obtained after four recharges were similar (4\%-7\% variation) to those obtained for the first run.

The effect of concentration was studied using two different substrate/catalyst ratios, namely 200/1 and 1000/1. When the substrate/catalyst ratio was 200/1 the catalytic reaction took place very rapidly which made it difficult to determine the conversion because it reached $100 \%$ in just 2 minutes of reaction. In contrast, when the substrate/catalyst ratio was raised to 1000/1, the system became heterogeneous in view of the difficulty of dissolving the substrate at this concentration.

The reaction was studied using two different bases to assess the effect of the base on the initial rate of the reaction. Figure 2 shows that if potassium terbutoxide is used the initial rate is higher than with sodium hydroxide; however, after 1 hour of reaction both bases reach similar activities above $90 \%$. When the complexes 3 and 4 were studied under similar conditions, the activities were low and the observed rate of conversion was $10 \%$ and $5 \%$, respectively, after 180 minutes of reaction.

Some authors have suggested mechanisms for the transfer hydrogenation [4-7]. In all of them, the formation of a hydride complex is critical in the hydrogenation process. The complexes used in this study contain a chloro ligand which is easily removed since it is a weak field ligand and thus allows the formation of the hydride complex. On the other hand, the complexes $\mathbf{3}$ and $\mathbf{4}$ contain a carbonyl group as 
the second ligand which is a strong field ligand thus making the reaction with the strong base more difficult.

Alternatively, we might consider that treatment of complex 1 or 2 with a strong base like KOtBu might as well result in abstraction of one chloro ligand (to yield $\mathrm{KCl}$ ) and deprotonation of one $\mathrm{NH}$, then propan-2-ol would re-protonate the P-N amido and transfer one hydride to $\mathrm{Ru}$. The resulting monohydride species may then hydrogenate the substrate during catalysis via an outer sphere mechanism. This pathway may be more difficult in complexes $\mathbf{3}$ and $\mathbf{4}$, which differ from $\mathbf{1}$ and $\mathbf{2}$ in the nature of the NPN ligand.

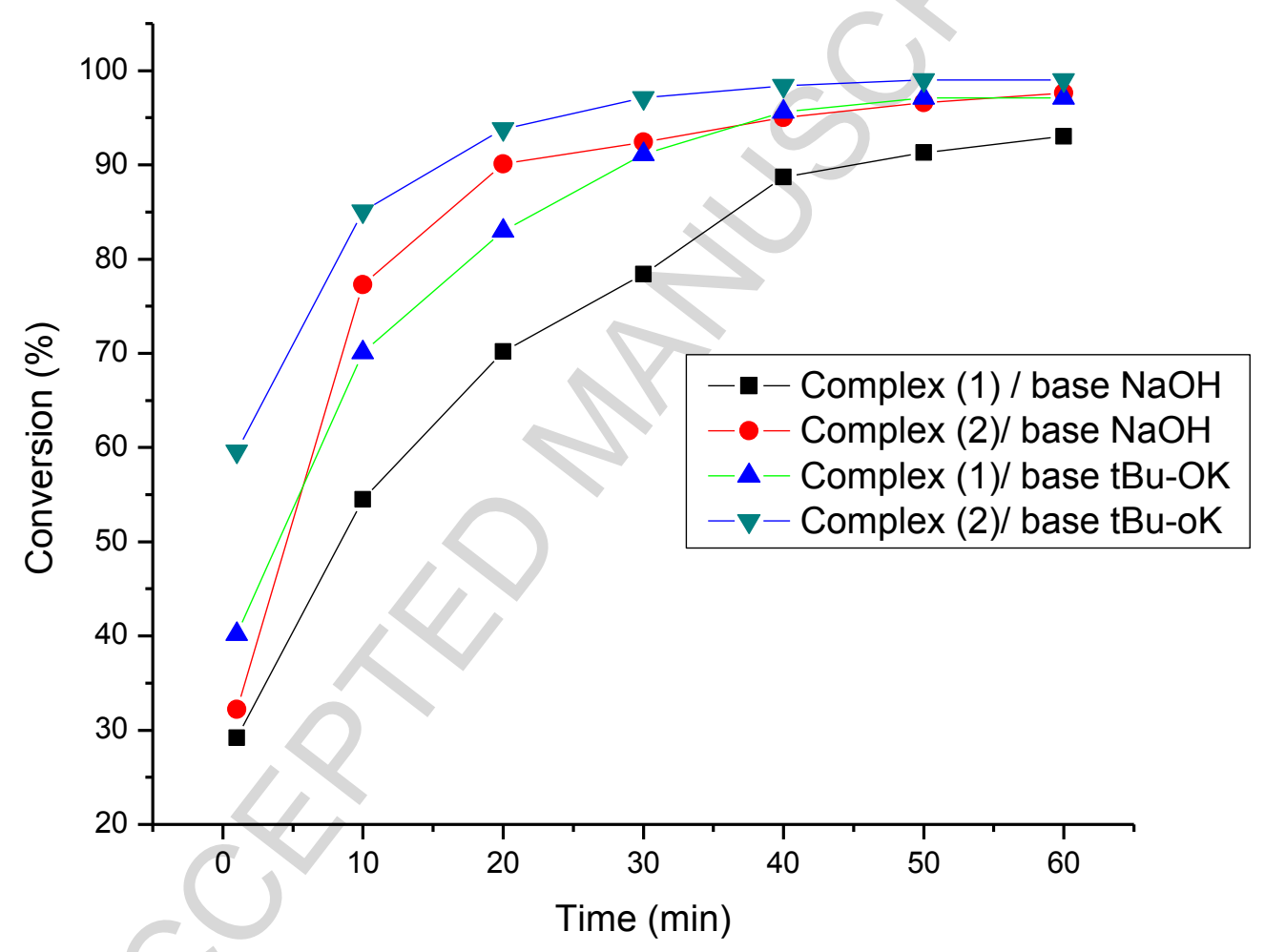

Figure 2. Catalytic activities of complexes $\mathrm{RuCl}_{2} \mathrm{PPh}_{3}\left(\mathrm{PPh}(\mathrm{NHPy})_{2}\right.$ (1) and $\left[\mathrm{RuCl}_{2} \mathrm{PPh}_{3}\left(\mathrm{PPh}(\mathrm{NHPyMe})_{2}\right)\right]$ (2) in the transfer hydrogenation of $\mathrm{N}$ benzylideneaniline using different bases. Temperature $50{ }^{\circ} \mathrm{C}$; substrate/catalyst ratio: 100/1.

For compounds 1 and 2 we observed a signal in the ${ }^{1} \mathrm{H}-\mathrm{NMR}$ at $-14 \mathrm{ppm}$ corresponding to a hydride species. This was detected by carrying out an experiment in which the catalyst was dissolved in refluxing propanol-2-ol with a 2/1 base/catalyst ratio after 5 minutes of reaction. Although the experiment was not 
carried out in catalytic conditions, this evidence might confirm that the catalytic reaction takes place via a Ru-hydride complex (see Supplementary Material).

We have demonstrated the formation of a ruthenium hydride by carrying out an experiment in which the catalyst was dissolved in refluxing propan-2-ol with a 2/1 base/catalyst ratio. For compounds $\mathbf{1}$ and $\mathbf{2}$ we observed a signal in the ${ }^{1} \mathrm{H}-\mathrm{NMR}$ at $-14 \mathrm{ppm}$ after 5 minutes of reaction, which would confirm that the catalytic reaction takes place via a Ru-Hydride (see Supplementary Material).

The results reported here for complexes 1 and 2 are comparatively better than those obtained by us with other catalysts for the same reaction [18-20]. The catalysts reported here represent an alternative in the transfer hydrogenation of $\mathrm{N}$ benzylideneaniline using ruthenium complexes containing pincer-type phosphorus nitrogen ligands.

\section{Conclusions}

Ruthenium complexes containing pincer-type phosphorus nitrogen ligands in a distorted octahedral geometry can be synthesized successfully using $\mathrm{RuCl}_{2}\left(\mathrm{PPh}_{3}\right)_{3}$ and $\mathrm{Ru}(\mathrm{Cl})(\mathrm{CO})(\mathrm{H})\left(\mathrm{PPh}_{3}\right)$ as starting materials. The NPN ligand in the complexes coordinates in a tridentate manner to the ruthenium metal via the pyridyl nitrogen and the phosphorus atom.

Complexes $\mathbf{1}$ and $\mathbf{2}$ are precursors of highly active catalytic systems for the transfer hydrogenation of $\mathrm{N}$-benzylideneaniline using propan-2-ol as the hydrogen source. The chloro ligand in complexes $\mathbf{1}$ and $\mathbf{2}$ facilitates the formation of a ruthenium hydride which is the active species in the reaction. On the other hand, complexes $\mathbf{3}$ and $\mathbf{4}$ are not active in the studied reaction because probably the carbonyl groups do not favor the generation of ruthenium hydride species or stabilize the catalyst precursor, not allowing the reaction with 2-propanol.

\section{Acknowledgments}

This work has been supported by ECOS-CONICYT (Action C14E02). The authors acknowledge the financial support provided by Fondecyt-Chile (project 1160505) and the valuable comments of Sergio Alegría (USACh). This research has been performed as part of the Chilean-French "Joint Laboratory for Inorganic Functional Materials" (LIAMIF $\mathrm{N}^{\circ}$ 386). One of the authors (S.A.M.) thanks, Dicyt of the Universidad de Santiago de Chile. 


\section{References}

[1] H. Doucet, T. Ohkuma, K. Murata, T. Yokozawa, M. Kozawa, E. Katayama, A.

F. England, T. lkariya, R. Noyori, Angew. Chem. 1998, 110, 1792-1796.

[2] T. Ohkuma, M. Koizumi, K. MuÇiz, G. Hilt, C. Kabuto, R. Noyori, J. Am. Chem. Soc. 2002, 124, 6508-6509.

[3] M. Vaquero, A. Suarez, S. Vargas, G. Bottari, E. Alvarez, and A. Pizzano, Chem. Eur. J. 2012, 18, 15586-15591.

[4] J. S. M. Samec, J. E. Backvall, P. G. Andersson and P. Brandt, Chem. Soc. Rev., 2006, 35, 237-248

[5] S. M. Samec and J. E. Backvall, Chem. Eur. J. 2002, 8, 13, 2955-2961.

[6] B. Zhao, Z. Han, and K. Ding, Angew. Chem. Int. Ed. 2013, 52, 4744-4788

[7] I. Scodeller, A. Salvini, G.Manca, A.Lenco, L.Luconi, W. Oberhauser, Inorg. Chim.Acta, 2015, 431, 242-247.

[8] S. Werkmeister, S. Fleischer, S. Zhou, K. Junge, and M. Beller, Chem. Sus.Chem. 2012, 5, 777-782.

[9]V. R. Sumerin, K. Chernichenko, M. Nieger, M. Leskel, B. Rieger, and T. Repo Adv. Synth. Catal. 2011, 353, 2093-2110.

[10] A. M. Kluwer, R. J. Detz, Z. Abiri, A. M. van der Burg and J. N. H. Reek, Adv. Synth. Catal. 2012, 354, 89-95.

[11] G. R Newkome, Chem. Rev., 1993, 93, 2067-2089

[12] R. Ramachandran, G. Prakash, M. Nirmala, P. Viswanathamurthi, J. G.

Malecki, J. of Organometallic Chem. 2015, 791, 130-140

[13] D. B.Garagorri, W. Lackner-Warton, C. M. Standfest-Hauser, K. Mereiter, K.

Kirchner, Inorg. Chim. Acta, 2010, 363, 3674-3679

[14] R. J. Lundgren, M.A Rankin, R. McDonald, G. Schatte, M.A Stradiotto, Angew. Chem., Int. Ed. 2007, 46, 4732-4735.

[15] M. Mastalir, M. Glatz, N. Gorgas, B. Stoger, E. Pittenauer, G. Allamier, L. F Veiros, and K. Kirchner, Chem. Eur. J. 2016, 22, 12316-12320.

[16] F. Foubelo, C. Nájera, M. Yus, Tetrahedron Asymmetry, 2015, 26, 769-790

[17 ] A. Mikhailine, M. I. Maishan, and R. H. Morris, Org. Lett., 2012, 14, 17 ,46384631.

[18] M. Vidal, S. A. Moya, C. Negrete-Vergara, G. Abarca, P. Aguirre, Inorg. Chem. Commun, 2012, 22, 146-148.

[19] C. Zúñiga, S. A. Moya, M. Fuentealba, B. Aranda, P. Aguirre, Inorg. Chem. Commun. 2011, 14, 964-967.

[20] S. A. Moya, J. C. Araya, J. Gajardo, V. Guerchais, L. Toupet, P. Aguirre, Inorg. Chem. Commun 2013, 27, 108-110.

[21] O. V. Dolomanov, L. J. Bourhis, R. J. Gildea, J. A. K. Howard, H. Puschmann, OLEX2: A complete structure solution, refinement, and analysis program, J. Appl. Crystallogr. 2009, 42, 339-341.

[22] M. Sheldrick, A short history of SHELX, Acta Crystallogr. Sect. A. Found. Crystallogr. 2017, 64, 112-122. 


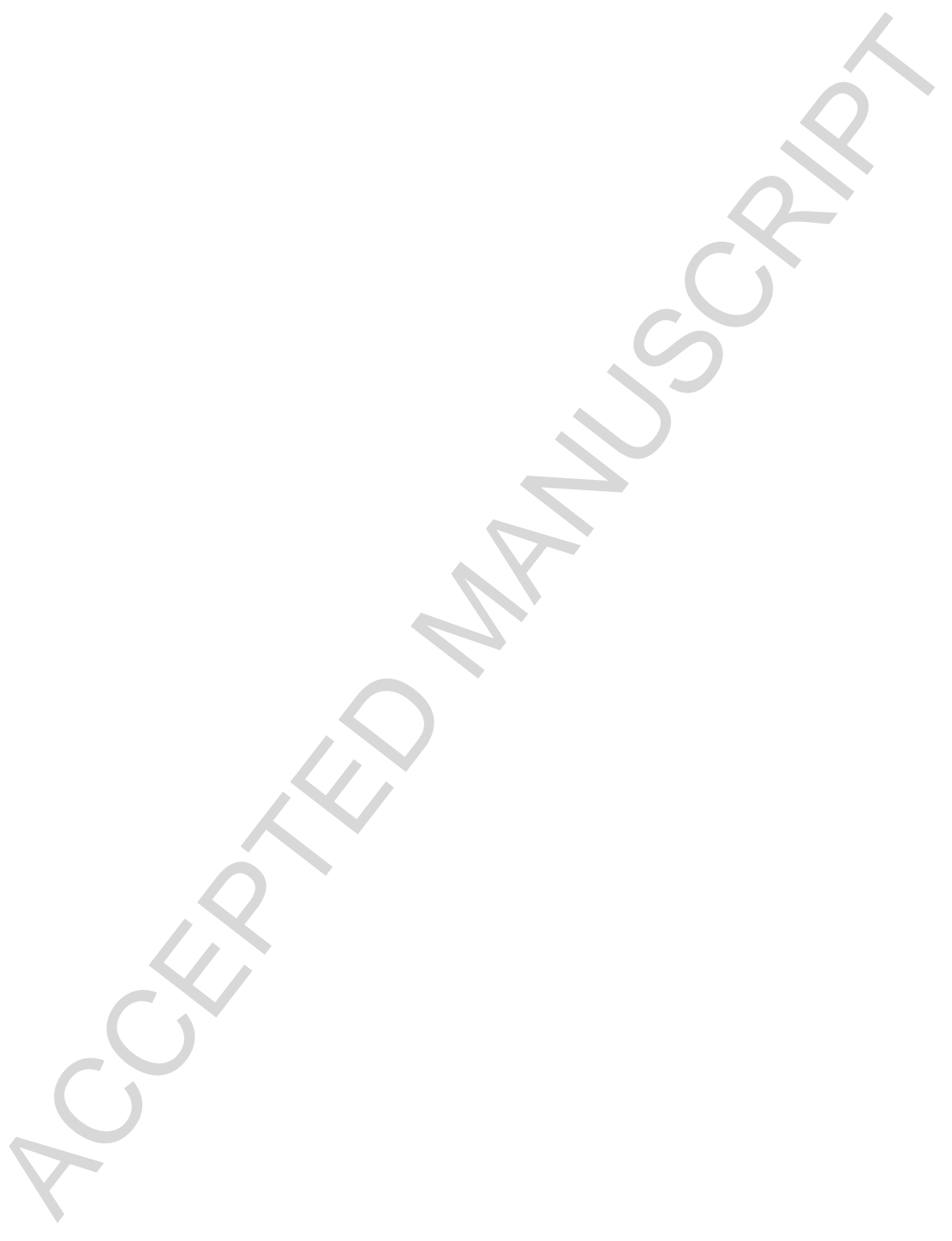




\section{Graphical Abstract}
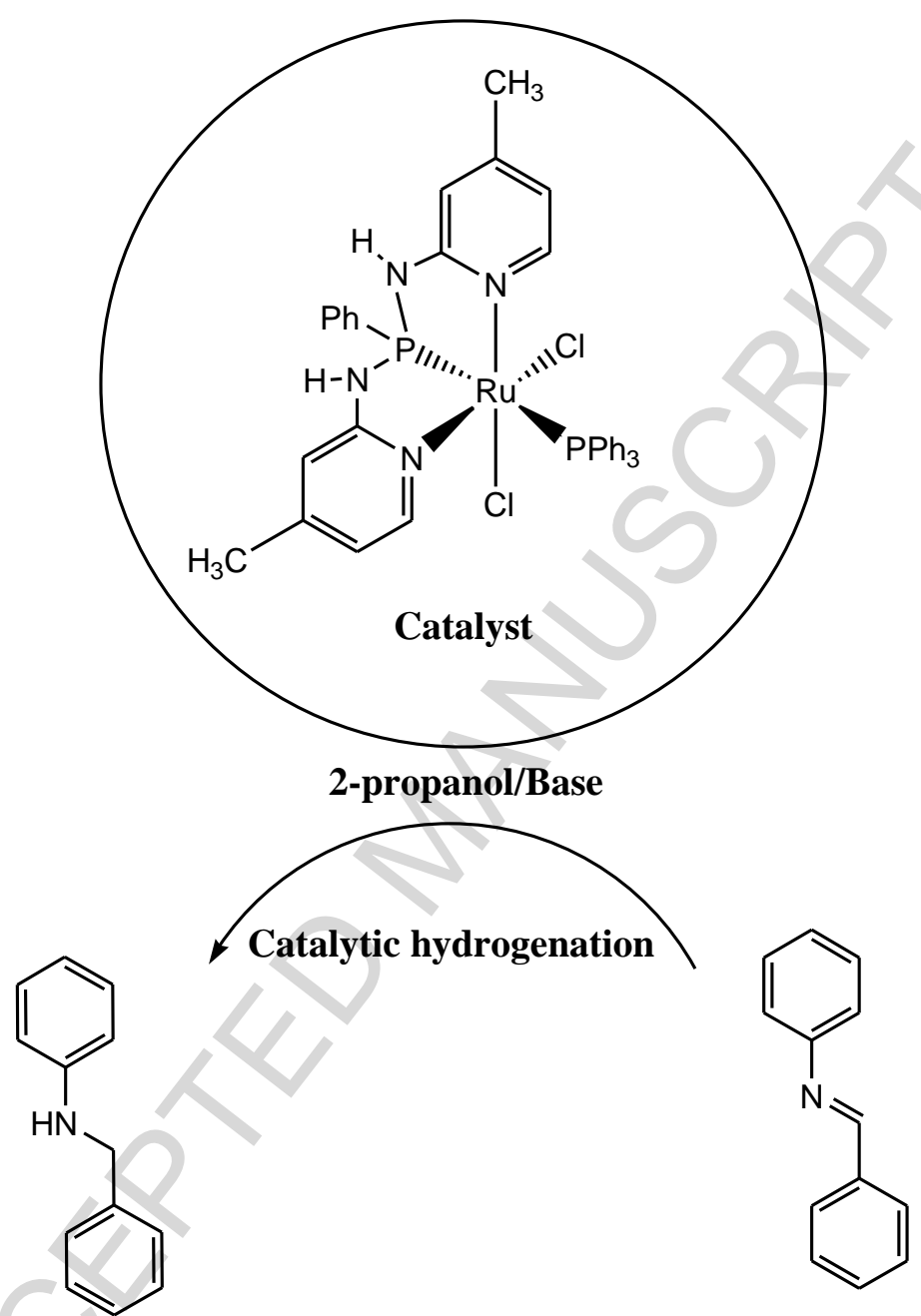


\section{Highlights}

- New Ru complexes containing pincer-type NPN ligands have been synthesized

- High activity is shown in transfer hydrogenation of $\mathrm{N}$-benzylideneaniline

- The catalytic reaction involves a Ru-hydride species. 